\title{
Web Tabanlı Yatırımcı Illişkileri Yönetimi Uygulamaları: Borsa İstanbul'da İşlem Gören Madencilik Sektörü Şirketlerine Yönelik Bir Analiz
}

\author{
Practice of Management Web-based Investor Relations: An Analysis of Mining \\ Sector Which Has Been Traded in Istanbul Stock Exchange
}

\author{
Doç. Dr. Fatih Temizel - Yrd. Doç. Dr. Sultan Fatih Kostakoğlu
}

\section{Öz}

İstanbul'un uluslararası finans merkezi olma hedefine doğru emin adımlar ile ilerlediği bir dönemde dünya finansal piyasaları iletişimde web tabanlı yatırımo ilişkileri yönetimi büyük önem kazanmaktadir. Bu çalışmada Madencilik Sektöründe faaliyet göstermekte olan ve pay senetleri Borsa İstanbul'da işlem gören şirketlerin web tabanl yatırımo ilişkileri yönetimi uygulamaları incelenmiştir. Adı geçen uygulamaların analiz edilme sürecinde Türkiye Yatırımcı İlişkileri Derneği tarafından geliştirilen skor kart kullanılmıştır. Skor kart içeriğinde yer alan başlıkların toplamda yüz yetmiş sorunun her birinin cevabı tek tek her şirketin web sitesinde aranmiştır. Var olan her uygulama ilgili şirkete bir puan kazandirirken olmayan her uygulama sifir puan kazandirmıştır. Incelenen şirketlerin puanları alt kategoriler ve genelde olmak üzere toplanmıştır. Puanlara dayah strlamalart ve puanlamanin detayları ile ilgili değerlendirmeler yapılmıştır. Bu kapsamda madencilik sektöründe en iyi web tabanl yatırımcı ilişkileri uygulamalarmın İhlas Madencilik A.Ş. (IHMAD) şirketinde olduğu belirlenmiştir. Aynı çalışmada diğer şirketlerin puanları hangi alanlarda topladıkları belirtilerek eksiklikler ortaya konmuştur. Gerek madencilik sektöründeki web tabanl yatırımcı ilişkileri yönetimi uygulamalarının gerekse en başarılı şirketin Borsa Istanbul genelindeki konumunu daha iyi belirleyebilmek ve anlamlandirabilmek için Borsa İstanbuldaki tüm şirketlerin web tabanl yatırımcı ilişkilerinin incelenmesi önerisi getirilmiştir.

Anahtar Kelimeler: Yatırımcı İlişkileri Yönetimi, İnternet, Madencilik Sektörü, Borsa İstanbul

\begin{abstract}
It is very important that Istanbul is an advance with sure steps towards its goal of becoming an international financial center period in world financial markets in the major communication management web-based investor relations. In this study, it is investigated webbased investor relations management practices of the companies which has been operating in the mining sector and stocks' has been trading in Istanbul Stock Exchange. At the process of analyzing practices we are talking about has used the scorecard developed by the Turkish Investor Relations Association. The answer to each question in a total of one hundred and seventy of the topics on the score card contents were sought in each individual company's website. The company earned 1 point for each existing application and earned zero point for each application which doesn't exist.
\end{abstract}

The points of companies which have been studied was collected with sub-categories and general. There was the evaluation of ranking according to the points and the details of scoring. According that, İhlas Mining (IHH$M A D)$ company is the best company has got the applications toward web-based investors. At the same study, it was stated which areas other companies collected points and recognized their minuses.

This study made an offer to examine the web-based investor relations at all companies which has been trading in Istanbul stock exchange, including here the mining based companies or all other good companies in Istanbul Stock Exchange.

Keywords: Investor Relations Management, Internet, Mining Sector, Istanbul Stock Exchange

Doç. Dr. Fatih Temizel, Anadolu Üniversitesi İİBF, ftemizel@anadolu.edu.tr

Yrd. Doç. Dr. Sultan Fatih Kostakoğlu, Anadolu Üniversitesi AÖF, sfkostagoglu@anadolu.edu.tr 


\section{Giriş}

Şirketlerin sermaye piyasalarındaki tanıtımı ve potansiyel farkındalıkların oluşumu büyük oranda yatırımcılarla sağlıklı ve sürekli iletişimin sağlandığı, güçlü ve üretken mesaj akışının gerçekleştiği bir mecrada sağlanabilmektedir. Halka arz edilen şirketlerin en büyük hedefi daha yüksek piyasa değerine ulaşabilmektir. Bu gerçek, yatırımcılar ile ilişkileri ve bunun doğal bir sonucu olarak yatırımcı ilișkileri yönetimi uygulamalarının önemini artırmaktadır.

Şirketlerin yatırımcılar ile iletişim kurma çabaları, potansiyel hissedarlara ulaşabilmek ve mevcut hissedarlarla sağlıklı iletişimin devamı için vazgeçilemezdir. Aynı zamanda gereksinimi her geçen gün daha çok fark edilen bir ihtiyacı karşılamayı hedeflemektedir.

Farkındalık ve hedef kitleye ulaşma çabasının en önemli aktörü olan web siteleri, yukarıda açıklanan nedenlerden dolayı araştırma konusu edilmiştir. $\mathrm{Bu}$ bilgiler doğrultusunda çalışmada Borsa İstanbul'da işlem gören Madencilik Sektörü Şirketlerinin web tabanlı yatırımcı ilişkileri yönetiminde kullandıkları araçlar; faaliyet raporları, web siteleri ve finansal sonuç açılama tabloları Türkiye Yatırımcı İlişkileri Derneği’nin (TÜYİD) hazırladığı Skor Kart’a göre analiz edilerek değerlendirilmiştir. Çalışmaya konu olarak madencilik sektöründe faaliyet gösteren şirketlerin seçilmesinin arka planında madencilik sektörünün Türkiye açısından artan öneminin yanı sıra sektörün en temel hedef kitlesinde profesyonellerin ağırlıkta olması yer almaktadır. Diğer bir ifade ile madencilik sektörü muhatapları arasında bireysel tüketicinin yer almamasıdır. Sektör yapısı itibarı ile profesyonellerden profesyonellere yönelik olarak faaliyet göstermektedir. Türkiye’de madencilik sektörünün genel görünümü Enerji Bakanlığı verileri ile aşağıda yer almaktadır.

Türkiye endüstriyel hammaddeler, metalik madenler, enerji hammaddeleri ve jeotermal kaynaklar aç1sından oldukça zengindir. Dünyada ticareti yapılan 90 çeşit madenden 77'si Türkiye'de yer almakta ve 60 civarında maden türünde üretim yapılmaktadır. Madencilik çeşitliliği göz önüne alındığında Türkiye dünyada 10 'uncu sırada yer almaktadır. Türkiye madenciliğini daha iyi noktalara taşımak amacıyla yapılan yasal düzenlemeler sayesinde Türkiye’nin maden kaynakları gerçek yatırımcılara açılmıştır. Bu durumun bir yansıması olarak, arama ve işletme ruhsat sayıları yıllar içinde azalırken maden satış gelirleri artış göstermiştir. Madencilik sektörünün ihracat ve milli gelir içindeki payı artmıştır.

Madencilik alanına yapılan yatırımlar ve teşviklerin bir sonucu olarak madenciliğin Gayri Safi Yurt İçi Hasıladaki payı son 13 yıl içinde \%1,1'den \%1,5 seviyelerine kadar yükselmiştir. Dünya bor rezervlerinin \%74'üne sahip olan Türkiye ürettiği ürünlerin \%97'sini dünyanın 100 den fazla ülkesinde yaklaşı 500 endüstriyel müşteriye ihraç etmekte olup dünya bor pazarında 2005 yllından itibaren piyasanın belirleyicisi ve lideri konumundadır. 2014 yilı verilerine göre Türkiye ihracatının \%2.9'unu karşılayan madencilik sektörü ülke ekonomisine toplamda 4.6 milyar USD gibi bir katkı sağlamaktadır.

Yukarıda açılandığı üzere Madencilik Sektörü Şirketlerinin muhatapları ağırlıklı olarak diğer endüstriyel şirketlerdir. Bu özellik yatırımcı ilişkileri yönetiminin özgün bir boyutunu oluşturmaktadır. Aynı nedenle ülke içi ve ihracat ekonomisine doğrudan önemli katkı sunan Madencilik Sektöründeki web tabanlı yatırımcı ilişkileri yönetimi uygulamalarını incelemek araştırma için önem arz etmektedir. Borsa İstanbul'da madencilik sektöründe halka arz edilen şirketlerin sayısı her geçen gün artmaktadır. Çalışmanın gerçekleştirildiği dönemde sektörün Borsa İstanbul'da işlem gören altı şirketi bulunmaktadır. Analiz ve değerlendirmeler bu şirketlerden bilgilerine ulaşılabilen beș tanesi üzerinde gerçekleştirilmiştir. Bu şirketler: İhlas Madencilik (İHMAD), İpek Doğal Enerji (İPEKE), Koza Madencilik (KOZAL), Metal Gayrimenkul (METAL) ve Park Elektrik Madencilik'ten (PRKME) oluşmaktadır.

\section{Literatür Taraması}

Günümüzde iletişim araçlarındaki çeşitlilik yatırımcıların bilgiye ulaşmasında kolaylık, sürat ve esneklik sağlarken, bilginin çokluğundan kaynaklanan bilgi kirliliğine de yol açmaktadır. Bu nedenle yatırımcıların doğru, zamanında ve güncel bilgiye sahip olması yatırımcıların bilgilendirilmesinde temel noktayı oluşturmaktadır (Bayram vd., 2009). Bilgiyi yatırımcılara hızlı ve doğru olarak ulaştırmada şirket web siteleri uygun bir mecra olarak kullanılmaktadır. İzleyen bölümde bu konuda dünyadaki farklı ülkelere ait uygulamaların değerlendirmelerinden bir özet sunulmaktadır. 
Seitel, internetin yatırımcı ilişkileri açısından bir devrim olduğunu ifade ederken, dünyanın neresinde ve hangi zamanda olursa olsun yatırımciların ilgilendikleri şirkete ilişkin bilgi sahibi olmalarının mümkün olduğunu belirtmektedir (Seitel, 2004, s. 371).

Jo ve Kim'in yüksek etkileşim ve multimedya özelliklere sahip olan web sitelerine ilişkin yaptıkları çalışma ile yüksek etkileşim özelliklerinin düşük etkileşim özelliklerine göre daha fazla olmasının, organizasyon ve yatırımcılar arasındaki ilişkiyi olumlu anlamda etkilediği belirlenmiştir (Jo ve Kim, 2003, s. 214-217). $\mathrm{Bu}$ durum, şirket web sitelerinin işlevsel bir biçimde tasarlanmasının, multimedya özellikleri ile donatılmasından daha önemli olduğunu ortaya koymaktadır.

Hong ve Kiousis, küçük ölçekli firmaların web siteleri üzerine yaptıkları çalışmada web sitelerinin sahip olması gereken başlıca beş özellikten söz etmektedir. Bunlar erişim, açıklık, içerik, yatırımcı desteği ve teknolojidir (Hong ve Kiousis, 2007, s. 25). Erişim; şirketlerin web sitelerinde yer alan yatırımcı linklerine kolay ulaşımın yanında posta, telefon, faks gibi iletişim araçları aracılığıyla sağlanan erişimi de içermektedir. Açıklık; şirkete ilişskin finansal verilerden, bilgilendirme ve kar dağıtım politikası gibi şirketin şeffaf yönetimini yansıtan verilere ulaşmayı kapsamaktadır. İçerik; bütün web sitelerinin birincil parçasını oluşturan ve yabancı dil seçeneğinden şirket tarihçesine, yatırımcıları ilgilendiren bilgileri işaret etmektedir. Yatırımcı desteği; yatırımcıların yardıma ihtiyacı olduğunda ya da herhangi bir ani gelişmede ulaşabilecekleri bağlantıları kapsamaktadır. Yatırımcı desteği, yatırımcıların memnuniyeti ve yatırımcı bağlılığ 1 açısından şirketlerin dikkat etmesi gereken, yatırımcı ilişkilerinin yüzünün yatırımcılara daha fazla dönük olmasını gerektiren bir konudur. Teknoloji ise, web sitelerinin yatırımcı ilişkilerinde ne kadar etkin olarak kullanıldığını ortaya koyan önemli uygulamalardan biridir.

Callison, Fortune 500 listesinde yer alan firmaların yatırımcı ilişkilerini şirket web sitelerini kullanarak nasıl kolaylaştırdığını araştırdığı çalışmasında, web sitelerinin, şirketlerin medya ile olan ilişkilerini sürdürme ve korumada kolaylaştırıcı bir etkisi olduğunu belirtmektedir. Medya ilişkileri, basın odası, haber odası, medya, basında çıkan haberler gibi çeşitli başliklar altında şirket web sitelerinde yer alan linkler, genellikle basın bültenlerini içermektedir (Callison,
2003, s. 40). Sanal basın odası olarak değerlendirilebilen bu ortamda, genel olarak şirkete ilişkin bilgiler, ürünlere ilişkin bilgiler, basın bültenleri, fotoğraflar ve iletişim bilgileri yer almaktadır (Theaker, 2006, s. 377). Lamb ve McKee, basin odası linkinin genellikle basın bültenlerini içermesine karşılık, temel düzeyde telefon numaraları ve e-postalar gibi iletişim bilgilerini kapsadığını belirtmektedir. Bununla birlikte daha iyi web sitelerinin mutlaka şu linkleri de içermesi gerektiğini söylemektedir: Şirkete ilişkin temel veriler, kurumsal tarih, yönetici biyografileri, yüksek çözünürlüklü yönetici resimleri, ürün ve faaliyet resimleri, anlaşılabilir grafik ve tablolar, dönemlik ve yıllık raporlar, yönetici konuşmaları, şirketin geçmişinde yer alan kilometre taşları olarak tanımlanabilecek önemli olaylar, gelecek etkinlikleri gösteren bir takvim bu kapsamdadır (Lamb ve McKee, 2004, s. 90). Gerek ulusal gerekse global ölçekte şirkete ilişkin bilgilere erişme konusunda web siteleri kadar medya ilişkilerinin düzenlenmesi ve yönetilmesi önem taşımaktadır.

Amerika Birleşik Devletleri Sermaye Piyasası Kurulu (SEC- Securities and Exchange Commission), üç ana başlığın yatırımcılarla şirket arasındaki iletişimde çok önemli olduğunu belirtmektedir (Wilcox vd., 2005, s.309):

- Şirketin hisse değerini etkileyebilecek herhangi bir şeye ilişkin mutlaka tam bilgi verilmesi. Şirketin hisse değerini etkileyebilecek olası gelişmeler ise, temettü, çeyrek dilim ve yıllık kazanç rakamları, hisse bölünmesi, şirket devralma ya da birleşme, yönetim değişikliği, ürün geliştirmeleri, genişleme planları, yönetim amaçlarının değişimi, taahhütleri yerine getirememe, vekaletle ilgili işlemler, aktiflerde değişim, şirketin kendi hisselerini satın alması, büyük iş bağlantıları, sipariş ya da alımların duyurulması olarak örneklendirilmektedir.

- Zamanında açılama yapmak. Bu amaçla elektronik basın bültenleri hazırlamak ya da uluslar arası haber ajansları aracılığılla duyurular yapmak.

- İçeriden bilgi sağlayarak işlem yapmak yasa dişıdır. Dolayısıyla yatırımcılar ve şirket arasındaki karşılıklı bilgi akışında bu maddelere uygun davranılması bir anlamda yasal bir zorunluluk olarak da ortaya çıkmaktadır. 
Kurumsal yatırımcilar iyi organize olmuş ve kontrol edilebilen yatırımcı ilişkileri programına sahip şirketlere yatırım yapma konusunda daha istekli olabilmektedir. Bu da yatırımcı ilişkilerinin kurumsal iletişimi temel parçası haline getirmiş ve "açı iletişim politikası"na sahip olmasını gerektirmektedir (Dolphin, 2004, s. 28). Amerika Birleşik Devletleri'nde yaşanan Enron, WorldCom gibi şirket skandallarından sonra şirket ve yatırımcıları arasında karşılıklı güvenin oluşturulması için yatırımcı ilişkileri yönetiminin gerekliliği ve önemi ortaya çıkmıştır (Laskin, 2009, s. 209). Şirket ve finansal topluluk arasındaki bilgi akış1 ise tek yönlü değil iki yönlü olmalıdır. Yatırımcılar şirkete ilişkin talep ettikleri bilgiyi yatırımcı ilişkileri uzmanlarından alırken, uzmanlar yatırımcılara ilişkin bilgi talebinde bulunabilmelidir.

Yatırımcı ilişkileri mevcut ve potansiyel yatırımcılar yanında finansal analistlere ve genel olarak finansal topluluğa devamlı, planlı, kısa ve uzun vadeli ilişkileri yapılandıracak ve sürdürecek bilgiler sunmalıdır. Daha geniş bir ifadeyle yatırımcı topluluğu ve işletme arasında doğrudan ya da dolaylı olarak ortak bir etkileşim ve bağlantı sağlamalıdır (Doplhin, 2004, s. 26). Yatırımcılar şirketlerin değerlendirilmesinde finans dışı boyutları giderek daha fazla dikkate almaya başlamıştır. Dolayısıyla şirketlere ilişkin yalnızca sayılar değil yapılan işin doğası, uzun dönemli stratejisi şirket hakkında finansal olmayan bilgiler de alım-satım kararlarında etkili olmaktadır (Laskin, 2009, s. 214). Tüm bu maddelerin ortak bir biçimde işaret ettiği konu ise yatırımcı topluluk ve şirket arasında açık iletişime bağlı, karşılıklı empati ve anlayışı gerektiren güven faktörünün tesis edilmesidir.

Theaker, Horton'dan web üzerinden gerçekleştirilen iletişim faaliyetlerinde gözetilmesi gereken 8 temel kural belirtmektedir. Bunlar basitlik, zamanlama, açıklık, tanımlama, esneklik, bireysellik, anlam, ölçülebilirliktir (Theaker, 2006, s. 361). Bunun yanında, şirketlerin iletişim faaliyetleri içinde diğer mecraları da kullanması beklenmektedir. Web üzerinden șirketlere ilișkin bilgilere ulaşmak isteyen yatırımcıların web sitesini ziyaret etme amacı iyi belirlenmiş olmalı ve yatırımcının aradığı bilgiyi kolayca ve çekici bir biçimde bulması gerekmektedir. Bir yatırımcı ulaşmaya çalıştı̆̆ı herhangi bir bilgiyi şirket web sitesinden kolaylıkla bulamıyor ya da ulaştığı bilgi kendisini tatmin etmiyorsa bir daha o siteyi ziyaret etmeyebilir. Bu da yatırımcı ilişkilerini web siteleri üzerinden yürütme- ye çalışan şirketler için olumsuz bir durum oluşturur.

Hedlin'in Stokholm Borsası'ndaki şirketlerin web sitelerinde yatırımcı ilişkilerini değerlendirdiği araştırması, şirketlerin üç aşamada web sitelerinin etkinliğini ortaya çıkardığını belirlemektedir. Öncelikle web sitelerinin oluşturulup çalışır duruma getirilmesi, sonrasında interneti kullanarak finansal bilginin yayılımının sağlanması ve son olarak web sitelerinin potansiyelinin değerlendirilerek kendine has özelliklerinin sağladığ $\breve{1}$ avantajların kullanımı ortaya çıkmaktadır. Bu eğilimin web sitelerinde genel olarak ortaya koyduğu özellikler ise finansal raporlar, hiper linkler, grafikler, basın bültenleri, yüklemeler, dinamik güncellemeler ve diğer dillerde sunulan bilgiler olarak belirtilebilir (Hedlin, 1999, s. 373-381). Hamid'in Kuala Lumpur Borsası'nda yaptığı benzer çalışmada ise şirket web sitelerinde yatırımcı ilişkileri linklerinin birincil amacının yatırımciları bilgilendirmek olduğu saptanırken web sitelerinde en fazla yer alan bilginin ise şirketin tarihçesi olduğu belirlenmiştir. Hamid, bunun yanında gelișmiş ve gelişmekte olan ülkelerin şirket web sitelerinde yatırımcı ilişkileri yönetimi açısından büyük ve önemli farklılıklar bulunduğunu belirtmektedir (Hamid, 2005, s. 5-14).

Şirketlerin web sitelerinde yayınladıkları finansal bilgileri, içinde bireysel yatırımcıların da bulunduğu geniş bir kullanıcı grubunun erişebileceği biçimde tasarlamaları önemlidir. Web siteleri, yatırımcı ilişkileri yönetiminde yönetici sunumlarından yönetim kurulu toplantı çağrılarına kadar geniş bir içeriği sunmaya uygundur. Web sitelerinin bir başka avantajı ise içinde grafik, metin, video ya da ses dosyalarını içeren çoklu format ve dildeki dokümanları talep eden yatırımcılara sunabilme potansiyelini taşımasıdır (Ettredge ve Gerdes, 2005, s. 95). Web sitelerinin sağladığı bu avantajlar kullanılırken aşırı bilgiye boğulmuş ya da iyi yönlendirme yapamayan bir tasarımdan kaçınılması webin etkin kullanımı için önemlidir. İçerik her zaman önemli bir faktör iken içeriğin tasarım, okunabilirlik, kullanılabilirlik gibi özellikleri gölgede bırakmaması gerekir.

Şirket web sitelerinin görsel tasarımının iyi düzenlenmiş olması, yönlendirme sisteminin iyi çalışması, geribildirim mekanizmalarının çabuk çalışması, kolay kullanım özellikleri taşıması az, öz ve alakalı bilgi taşıması temel özellikler olarak sayılabilir. Ekrandan okumak kağıttan okumaktan daha zor olduğu için 
metinler çok uzun tutulmamalı; ayrıntılı bilgiye ihtiyaç duyulması halinde bu bilginin e-posta aracılığıyla sağlanabilmesi; dünyanın dört bir yanından farklı dillerde bireylerin web sitesini ziyaret etme olasılığının düşünülmesi etkin bir web sitesi için önemlidir (Theaker, 2006, s. 371-373).

\section{Yöntem ve Veri Seti}

Türkiye Yatırımcı İlişkileri Derneği (TÜYİD), Türkiye'de yatırımcı ilişkileri ile farklı hedef kitleleri kurumsal ve bireysel platformda bir araya getirerek, mesleki bilgi üretmek ve yatırımcı ilişkileri uygulamalarında dünya standartlarına ulaşmak amacıyla kurulmuş bir kurumdur. Misyonunu, Türkiye piyasalarının ve şirketlerinin yatırımcılara en iyi şekilde tanıtılmasına ve şirketlerin adil piyasa değerlerine ulaşmalarına katkıda bulunmak ve Türkiye sermaye piyasalarının derinlik kazanmasını desteklemek şeklinde açıklamaktadır. Web siteleri özelinde yatırımcı ilişkileri yönetimi uygulamalarının araştırma ve ölçümlerinin sağlıklı bir şekilde yapılabilmesi adına bir Skor Kart çalışması gerçekleştirmiştir. Şirketlere sorulacak 170 (bankalar için 186) soruyu barındıran Skor Kart; faaliyet raporu (66), finansal sonuç açılama (45) ve web sitesi (59) soru içeren toplam üç bölümden oluşmaktadır. Çalışmada bu skor kart arac1lığı ile veri toplanmıştır.

Faaliyet Raporu kategorisinde yatırımcı ilişkileri yönetiminde bilgilendirme konusunda hayati önem arz eden yıllık faaliyet raporlarının içeriğinde olması gereken bilgiler ve bu bilgilerin yeterliliği test edilmektedir. Şirketin stratejik hedefleri, sermaye, kar payı dağıtım politikası, sosyal sorumluluk anlayışı, kurumsal yönetime uyum beyanları gibi konulara değinen faaliyet raporu soruları, şirketlerin yatırımc1larla ne denli sağlıklı ve sürekli bir iletişim kurduğunu açılklar nitelikte sorulardır. Araştırmada incelenen şirketlerin web sitesinde yayınladığ yet raporu Türkçe ve İngilizce dillerinde incelenmiş ve verilerin güncel olması önemsenmiştir.

Finansal Sonuç Açılama kategorisinde internet siteleri, basın bültenleri, yatırımcı sunumları ve faaliyet raporları incelenmiştir. Yatırımcıların yatırım girişimleri esnasında oldukça önem verdikleri şirketin mali durumu, gelişimi ve öngörüleri konusunda şeffaf bir yaklaşımla kendileriyle iletişim kurmalarını beklediği şirketler için bu kategorideki sorular ve cevapları yatırımcı ilişkileri yönetimini ne kadar doğru yaptıklarını gösterir niteliktedir. Geçmiş yıllardaki mali yapılar, çeyreksel finansal analizler, kar marjları, satış, fiyatlandırma ve hisse senetleri gibi başlıklara sahip olan Finansal Sonuç Açıklama kategorisinde incelemeler şirketin web sitesinde yayınlanan son raporlardan alınan bilgiler doğrultusunda gerçekleştirilmiş ve güncel bilgiler sağlanmaya çalışılmıştır.

Web Sitesi kategorisinde şirketler ve yatırımcılar arasında direkt bir iletişim sağlanabilmesi için önemi büyük olan internet sayfalarının içerik analizinde sorulan 59 soru genel hatlarıyla, 'yatırımcılar şirket için önemli mali bilgilere ulaşabiliyor mu?', 'yatırımcılar şirketin genel kurul bilgilerine ulaşabiliyor mu?', 'yatırımcılar için özel sunumlar hazırlanmış mı?', 'web sitesi teknoloji ve yeni iletişim araçlarını doğru bir şekilde kullanabiliyor mu?', 'Yatırımcının ulaşması gereken bilgi ve belgeler diğer sitelere (KAP vb.) yönlendirme yapmanın yanı sıra web sitelerinde de mevcut mu?' şeklinde sorulan sorulardır.

İncelemede cevaplar "VAR", "YOK" veya "UYGULANAMAZ" şeklindedir. Puanlama, "VAR" cevabı verilen sorulara 1 puan, "YOK" cevabı verilen sorulara 0 puan şeklinde gerçekleştirilmiştir. Her bir şirketin puanları yukarıda belirtilen üç kategori altında ayrı ayrı toplanarak oluşturulmuştur. 


\section{Bulgular}

Tablo 1. Faaliyet Raporu Sonuçları

\begin{tabular}{|c|c|c|}
\hline Şirketler & $\begin{array}{c}\text { Faaliyet Raporu } \\
\text { Skor Kart Puanı }\end{array}$ & $\begin{array}{c}\text { Faaliyet Raporu } \\
\text { Skor Kart Siralaması }\end{array}$ \\
\hline İhlas Madencilik (İHMAD) & 56 & 2 \\
\hline Park Elektrik Madencilik (PRKME) & 55 & 3 \\
\hline Koza Altın (KOZAL) & 49 & 4 \\
\hline Metal Gayrimenkul (METAL) & 46 & 5 \\
\hline İpek Doğal Enerji (İPEKE) & 0 & \\
\hline
\end{tabular}

Skor Kart incelemesinde Borsa İstanbul'da işlem gören Madencilik Sektörü’ndeki 5 şirketin Faaliyet Raporu Kategorisinde 66 soruluk inceleme yapılmıştır.

Skor Kart incelemesi sonucunda, Skor Kart çalışmasının Faaliyet Raporu Kategorisinde bu 5 şirketin s1ralaması tablo 1'deki gibi olmuştur.

Faaliyet Raporu Kategorisindeki soru başlıkları:

- Kurumsal Yönetim İlkeleri; 42 soru

- Faaliyet İçerikleri ve Görsellik; 24 soru

İhlas Madencilik (İHMAD): Kurumsal Yönetim İlkeleri 41/42, Faaliyet İçerikleri ve Görsellik 15/24
Park Elektrik Madencilik (PRKME): Kurumsal Yönetim İlkeleri 37/42, Faaliyet İçerikleri ve Görsellik $18 / 24$

Koza Altın (KOZAL): Kurumsal Yönetim İlkeleri 32/42, Faaliyet İçerikleri ve Görsellik 17/24

Metal Gayrimenkul (METAL): Kurumsal Yönetim İlkeleri 30/42, Faaliyet İçerikleri ve Görsellik 16/24

İpek Doğal Enerji (İPEKE): Şirketin faaliyet raporlarına web sitelerinden erişim yapılamadığ 1 için Skor Kart çalışması gerçekleştirilememiştir.

Tablo 2. Finansal Sonuç Açıklama Sonuç

\begin{tabular}{|c|c|c|}
\hline Şirketler & $\begin{array}{c}\text { Finansal Sonuç Açılama } \\
\text { Skor Kart Toplam }\end{array}$ & $\begin{array}{c}\text { Finansal Sonuç Açıklama } \\
\text { Skor Kart Siralaması }\end{array}$ \\
\hline Metal Gayrimenkul (METAL) & 32 & 2 \\
\hline İhlas Madencilik (İHMAD) & 30 & 3 \\
\hline Koza Altın (KOZAL) & 30 & 4 \\
\hline Park Elektrik Madencilik (PRKME) & 24 & 5 \\
\hline İpek Doğal Enerji (İPEKE) & 20 & \\
\hline
\end{tabular}


Skor Kart incelemesinde Borsa İstanbul'da işlem gören Madencilik Sektörü’ndeki 5 şirketin Finansal Sonuç Açıklama Kategorisinde 45 soruluk inceleme yapılmıştır.

Skor Kart incelemesi sonucunda, Skor Kart çalışmasının Finansal Sonuç Açıklama Kategorisinde bu 5 şirketin sıralaması tablo 2'deki gibi olmuştur.

\section{Finansal Sonuç Açıklama Kategorisindeki soru başlıkları}

-Şirket Hakkında Diğer Önemli Gelişme ve Bilgiler; 19 soru

-Mali Tablolar; 14 soru

-Hesap Dönemi Hakkında Önemli Bilgiler; 12 soru

Metal Gayrimenkul (METAL): Şirkete Hakkında
Diğer Önemli Gelişme ve Bilgiler 11/19, Mali Tablolar 12/14, Hesap Dönemine Ait Önemli Bilgiler 9/12

İhlas Madencilik (İHMAD): Şirkete Hakkında Diğer Önemli Gelişme ve Bilgiler 9/19, Mali Tablolar 12/14, Hesap Dönemine Ait Önemli Bilgiler 9/12

Koza Altın (KOZAL): Şirkete Hakkında Diğer Önemli Gelişme ve Bilgiler 9/19, Mali Tablolar 13/14, Hesap Dönemine Ait Önemli Bilgiler 8/12.

Park Elektrik Madencilik (PRKME): Şirkete Hakkında Diğer Önemli Gelişme ve Bilgiler 7/19, Mali Tablolar 11/14, Hesap Dönemine Ait Önemli Bilgiler 6/12

İpek Doğal Enerji (İPEKE): Şirkete Hakkında Diğer Önemli Gelişme ve Bilgiler 4/19, Mali Tablolar 10/14, Hesap Dönemine Ait Önemli Bilgiler 6/12

Tablo 3. Web Sitesi Sonuç

\begin{tabular}{|c|c|c|}
\hline Şirketler & $\begin{array}{c}\text { Web Sitesi } \\
\text { Skor Kart Toplam1 }\end{array}$ & $\begin{array}{c}\text { Web Sitesi } \\
\text { Skor Kart Stralaması }\end{array}$ \\
\hline İhlas Madencilik (IHHMAD) & 33 & 1 \\
\hline Park Elektrik Madencilik(PRKME) & 31 & 2 \\
\hline Metal Gayrimenkul(METAL) & 30 & 3 \\
\hline İpek Doğal Enerji (İPEKE) & 28 & 4 \\
\hline Koza Altın (KOZAL) & 28 & 5 \\
\hline
\end{tabular}

Skor Kart incelemesinde Borsa İstanbul'da işlem gören Madencilik Sektöründeki 5 şirketin Web Sitesi Kategorisinde 59 soruluk inceleme yapılmıştır.

Skor Kart incelemesi sonucunda, Skor Kart çalışmasının Web Sitesi Kategorisinde bu 5 şirketin sıralamas1 tablo 3’teki gibi olmuştur.

\section{Web Sitesi Kategorisindeki soru başlıkları:}

-İçerik; 30 soru

-Yoğunluk; 23 soru

-Teknoloji; 6 soru
İhlas Madencilik (İHMAD): İçerik 23/30, Yoğunluk 8/23, Teknoloji 2/6

Park Elektrik Madencilik (PRKME): İçerik 23/30, Yoğunluk 6/23, Teknoloji 2/6

Metal Gayrimenkul (METAL): İçerik 23/30, Yoğunluk 4/23, Teknoloji 3/6

İpek Doğal Enerji (İPEKE): İçerik 20/30, Yoğunluk 7/23, Teknoloji 1/6

Koza Altın (KOZAL): İçerik 20/30, Yoğunluk 7/23, Teknoloji 1/6 


\section{Sonuç}

Tablo 4. Skor Kart Genel Toplam Puanları

\begin{tabular}{|c|c|c|}
\hline Şirketler & $\begin{array}{c}\text { Skor Kart } \\
\text { Genel Toplam }\end{array}$ & $\begin{array}{c}\text { Skor Kart } \\
\text { Genel Siralama }\end{array}$ \\
\hline İhlas Madencilik (IHMAD) & 119 & 1 \\
\hline Park Elektrik Madencilik (PRKME) & 110 & 2 \\
\hline Metal Gayrimenkul (METAL) & 108 & 4 \\
\hline Koza Altın (KOZAL) & 107 & 5 \\
\hline İpek Doğal Enerji (İPEKE) & 48 & 3 \\
\hline
\end{tabular}

Skor Kart incelemesinde Borsa İstanbul'da işlem gören Madencilik Sektörü’ndeki 5 şirketin her biri için Faaliyet Raporu, Finansal Sonuç Açıklama ve Web Sitesi Kategorilerinde toplamda 170 soruluk inceleme yapılmıştır.

Skor Kart incelemesi sonucunda Skor Kart çalışmasının genel skor toplamlarında bu 5 şirketin sıralaması tablo 4’teki gibi olmuştur.

Faaliyet raporu erişimi sağlanamayan İpek Doğal Enerji şirketinin düşük skoru haricinde Madencilik Sektöründe şirketlerin skorlarının birbirlerine yakın olduğunu görülmektedir. Üç kategorinin ikisinde (faaliyet raporu ve web sitesi)ilk sırayı, genel skor toplamında da olduğu gibi İhlas Madencilik (İHMAD) almıştır. Finansal sonuç açılama kategorisinde ise en yüksek skoru genel skor toplamında 3. sırada yer alan Metal Gayrimenkul (METAL) almıştır. Park Elektrik Madencilik (PRKME), 3 kategoride de ortalama ve üstü puanlar alarak genel skor toplaminda 2. sirada yerini almıştır. Koza Altın (KOZAL), 3 kategoride de ortalama ve altı puanlar alarak genel skor toplamında 4. sırada yer alabilmiştir. İpek Doğal Enerji (İPEKE), faaliyet raporuna erişilememesi ve diğer iki kategoriden de en az puanı alması sebebiyle genel skor toplamında son sırada yer almıştır.

Çalışma sonucunda Madencilik Sektörü’ndeki 5 şirketin kategoriler ve alt başlıklarından aldıkları puanlar aşağıda detaylı bir şekilde sunulmaktadır.

İhlas Madencilik (İHMAD): Faaliyet raporu 56 (kurumsal yönetim ilkeleri 41/42, faaliyet içerikleri
15/24), finansal sonuç açıklama 30 (şirkete hakkında diğer önemli gelişme ve bilgiler 9/19), mali tablolar $12 / 14$, hesap dönemine ait önemli bilgiler 9/12), web sitesi 33 (içerik 23/30, yoğunluk 8/23, teknoloji $2 / 6$ ); 119.

Park Elektrik Madencilik (PRKME): Faaliyet raporu 55 (kurumsal yönetim ilkeleri 37/42, faaliyet içerikleri 18/24), finansal sonuç açıklama 24 (şirkete hakkında diğer önemli gelişme ve bilgiler 7, mali tablolar 11, hesap dönemine ait önemli bilgiler 6), web sitesi 31 (içerik 23/30, yoğunluk 6/23, teknoloji 2/6); 110

Metal Gayrimenkul (METAL): Faaliyet raporu 46 (kurumsal yönetim ilkeleri 30/42, faaliyet içerikleri 16/24), finansal sonuç açıklama 32 (şirkete hakkında diğer önemli gelişme ve bilgiler 11/19, mali tablolar $12 / 14$, hesap dönemine ait önemli bilgiler $9 / 12$ ), web sitesi 30 (içerik 23/30, yoğunluk 4/23, teknoloji $3 / 6$ ); 108.

Koza Altın (KOZAL): Faaliyet raporu 49 (kurumsal yönetim ilkeleri 32/42, faaliyet içerikleri 17/24), finansal sonuç açıklama 30 (şirket hakkında diğer önemli gelişme ve bilgiler 9/19, mali tablolar 13/14, hesap dönemine ait önemli bilgiler 8/12), web sitesi 28 (içerik 20/30, yoğunluk 7/23, teknoloji 1/6); 107.

İpek Doğal Enerji (İPEKE): Faaliyet raporu 0, finansal sonuç açıklama 20 (şirket hakkında diğer önemli gelişme ve bilgiler $4 / 19$, mali tablolar $10 / 14$, hesap dönemine ait önemli bilgiler 6/12), web sitesi 28 (içerik 20/30, yoğunluk 7/23, teknoloji 1/6); 48. 
Elde edilen puanlara göre Madencilik Sektörü’nde web tabanlı yatırımcı ilişkileri uygulamalarında en başarılı şirketin İhlas Madencilik (İHMAD) olduğu görülmektedir. Sektörün diğer temsilcilerinin de İhlas Madencilik'i (İHMAD) yakından izlediği belirlenmiştir. İpek Doğal Enerji (İPEKE) bu gruptan ayrilmaktadır. Sektör temsilcilerinin birbirine yakın uygulamalarının detaylı yorumlanabilmesi için Borsa İstanbul'da kayıtlı diğer sektör temsilcilerinin uygulamalarının da analiz edilmesi önerilebilir. Böylece daha büyük bir veri seti içinde Madencilik Sektörünnün konumu değerlendirilebilir. Uygulamanın bu bakış açısı ile Borsa İstanbul'da işlem gören tüm şirketlere yaygınlaştırılması araştırmacıların bundan sonraki hedefi olarak belirlenmiştir.

\section{Kaynakça}

Aydın, N. (Ed.) (2009). Kamuoyunun Aydınlatılmasında Yatırımcı İlişkileri. Anadolu Üniversitesi Yayınları, Eskişehir, 20/10/2009

Bayram, F., Temizel F., \& Sarıkaya, M. (2009). "Yatırımcı İlişkileri Yönetimi: Bir Halkla İlişkiler Aracı Olał rak Kullanımı ve Değerlendirilmesi” 1. Uluslararası Halkla İlişkiler Sempozyumu. [sunulmuş bildiri] Girne, KKTC, 17 Nisan 2009.

Callison, C. (2003). "Media Relations and the Internet: How Fotrune 500 Company Web Sites Assist Journalists in News Gathering" Public Relations Review. 29: 29-41, 2003.

Dolphin, R., R. (2004). “The Strategic Role of Investor Relations" Corporate Communicaitons: An International Journal. Vol: 9 No: 1: 25-42, 2004.

Ettredge, M. \& Gerdes, J. Jr. (2005). “Timeliness of Investor Relations Data at Corporate Web Sites" Communications of the ACM. Vol: 48 No:1: January 2005.

Hamid, F. Z. A., (2005). “Malaysian Companies' Use of the Internet for Investor Relations" Corporate Governance. Vol: 5 No: 1: 5-14, 2005.
Hedlin, P. (1999). "The Internet as a Vehicle for Investor Relations: The Swedish Case" The European Accounting Review. 8: 2: 373-381, 1999.

Hong, Y. S., \& Spiro, K. (2007)."Relationship Maintenance with Financial Publics: An Analysis of Investor Relations on Small Companies' Web Sites" International Communication Association. [sunulmuş bildiri] TBA, San Francisco: CA, 23 Mayıs, 2007.

Jo, S. \& Yungwook, K. (2003). "The Effect of Web Characteristics on Relationship Building" Journal of Public Relations Research. Vol: 15, No: 3: 199223, 2003.

Lamb, L. F., \& Kathy, B. M. (2004). Applied Public Relations: Cases in Stakeholder Management. New Jersey: Lawrence Erlbaum, 2004.

Laskin, A. V. (2009). "A Descriptive Account of the Investor Relations Profession: A National Study" Journal of Business Communication. Vol: 46, No: 2: 208-233, April 2009.

Seitel, F. P. (2004). The Practice of Public Relations. New Jersey: Prentice Hall, 2004.

Theaker, A. (2006). Halkla İlişkilerin El Kitabı. Çeviren: Murat Yaz, İstanbul: MediaCat Yayınları, 2006.

Türkiye Yatırımcı İlişkileri Ödülleri 2014 Bilgilendirme Kitapçı̆̆ı, Türkiye Yatırımcı İlişkileri Derneği, 2014

Wilcox, D. L., Cameron, G. T., Ault, P. A. \& Agee, W. K. (2005) Public Relations Strategies and Tactics. Boston: Pearson Inc, 2005.

www.tuyid.org 